\title{
The Unit Phrase in Mandarin
}

\author{
YU-YIN HSU
}

Bard College ${ }^{I}$

\section{Introduction}

Since Cheng and Sybesma (1998, 1999), the syntax, the headedness of measure words, and the semantic distinction of them (i.e., "classifiers" vs. "massifiers") have aroused great discussion. The measure words at issue refer to words that serve as a unit or measurement of nouns for counting purposes. ${ }^{2}$ According to Cheng and Sybesma (1998), measure words can be distinguished semantically with respect to the noun that they are associated with. Count nouns refer to entities "which present themselves naturally in discrete, countable units," and mass nouns are "substances which do not present themselves" in specific units. Based on this, Chen and Sybesma divide measure words into two types: measure words like (1a) are referred as "classifier," and those like (1b) are referred as "massifier."

$\begin{array}{llll}\text { a. } & \begin{array}{l}\text { liang ben shu } \\ \text { two CL book } \\ \text { 'two books' }\end{array} & \\ & & & \\ \text { b. } & \text { san xiang } & \text { shu } \\ & \text { three CL.box } & \text { book } \\ & \text { 'three boxes of books' }\end{array}$

Various structures have been proposed to account for Chinese nominal expressions containing a classifier/massifier: a unified left-branching structure (e.g., Huang 1982, Tang 1990, Hsieh 2008, and Her 2012, as in (2)), a unified right-branching structure (e.g., Tang 1990, Cheng and Sybesma 1999, Borer 2005, Huang, Li and Li 2009, as in (3)), and non-unified accounts that usually propose a structure like (2) for "massifier" and a structure like (3) for "classifier" (e.g., Zhang 2011, 2013, X. Li 2011, and X. Li and Rothstein 2012). In this paper, unlike the previous syntactic analyses, I argue for a different and simplified right-branching structure that can account for the syntax of the measure words in question.

1 I benefit a lot from Steven Franks, Yoshihisa Kitagawa, and Jen Ting for discussions and comments on the earlier drafts of this paper. I also thank Peter Jenks, Line Mikkelsen, and the audience of BLS 40 for their insightful comments and suggestions. Any errors and inadequacies are exclusively my own.

2 The abbreviations of the glosses used in examples are: CL, classifier, measure word; DE, marker of modifiers of nominal expressions; PERF, perfective aspect marker; EXP, experienced aspect marker. 


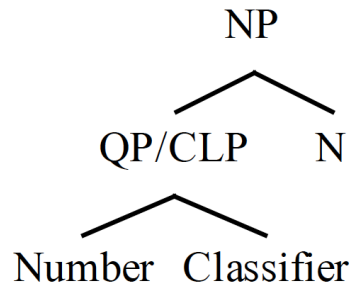

(3) Right-branching Structure

NumberP

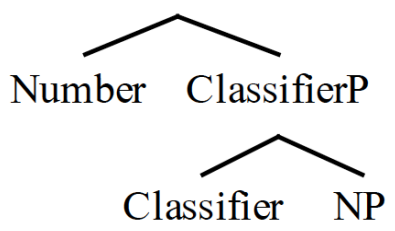

Before I present my analysis, there are facts that suggest the uniformity of massifiers and classifiers from a syntactic perspective. To begin, it is well known that different types of measure words (i.e., classifiers and massifiers) cannot co-occur. The examples in (4) demonstrate this point. Such examples suggest that these measure words compete for the same syntactic position.
a.* liang ben xiang shu
two CL CL.box book
b.* liang xiang ben shu
two CL.box CL book

Moreover, it has been pointed out in Tang (2005), Hsiech (2008), Her (2012) and Shi (2013) that both classifiers and massifiers are compatible with the so-called "de-insertion," which was originally argued by Cheng and Sybesma (19999) as a syntactic difference between massifiers and classifiers. ${ }^{3}$

3 Following Tang (1990), I assume that the sequence of number-classifier-de (e.g., (i)) is analyzed as modifier phrase (ModP) on a par with other modifier of nominals (e.g., adjectives and relative clauses), which is different from the typical classifier structure that is discussed in this paper (e.g., (ii)), i.e., UnitP proposed in this study.

(i) [ModP liang bang de] [NP rou ] two pound DE meat

'meat that is sorted in accordance with two pounds'

(ii) [UnitP liang bang rou] two pound meat

'two pounds of meat' 

a. yi da tiao de yu
one big $\mathrm{CL}$ DE fish
'one big fish'

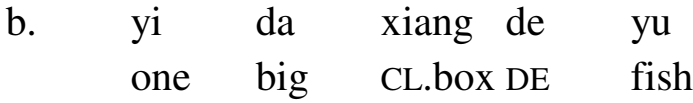
'one big box of fish'

Zhang $(2011,2013)$ and Her (2012) also show that both classifiers and massifiers can license NP ellipsis. The examples in (6) demonstrate this point.
$\begin{array}{lllllllll}\text { a. Ta } & \text { you } & \text { san } & \text { ben } & \text { shu, } & \text { wo } & \text { you si } & \text { ben sht. } \\ \text { He } & \text { have } & \text { three } & \text { CL } & \text { book } & \text { I } & \text { have } & \text { four } & \text { CL }\end{array}$ 'He has three books, I have four.'
$\begin{array}{llllllll}\text { b. Ta } & \text { you san } & \text { xiang shu, wo } & \text { you si } & \text { xiang shu. } \\ & \text { He } & \text { have three } & \text { CL.box book } & \text { I } & \text { have four CL.box }\end{array}$ 'He has three boxes of books, I have four boxes.'

Therefore, although I acknowledge that there are several semantic differences that could be identified among the measure words at issue, such as the count-mass distinction argued in Cheng and Sybesma (1998, 1999), or interpretations of container, partitive, collective, and individuating functions that are discussed in Zhang (2011, 2013), I argue that a simplified unified rightbranching structure can explain the syntax and account for the same range of data reported in the literature. As shown in (7), my proposal presents the measure words at issue as the head of a Unit Phrase (hence UnitP) dominating noun phrase (hence NP) and taking numeral phrase (hence NumP) as its specifier.

(7) Proposal: Unit Phrase

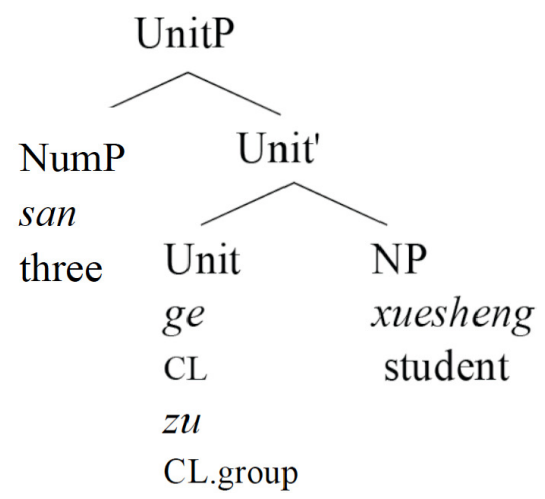


Structures similar to (7) can be found in non-unified accounts, such as Cheng and Sybesma (1998), Zhang (2011, 2013), X. Li (2011), and X. Li and Rothstein (2012). Independently, Zhang (2013) also proposes the same UnitP structure but only proposes it for measure words that express individual or individuating interpretation. However, I depart from these proposals and argue that this structure (7) alone can explain the syntactic behaviors of measure words. More importantly, unlike the previous analyses, I argue that the occurrence of Unit head changes the semantic core of the whole nominal expression, that the projection UnitP is independent of and dominates the complement NP, and that modification of adjectives within a nominal expression has to respect this structure.

In the following sections, I discuss why I render previous proposals using left-branching structures not plausible, and why the current proposed structure (7) can account for the same set of data in a simpler way.

\section{Problems in Left-Branching Proposals}

In this section, I show that a left-branching structure is neither plausible nor required, and therefore, non-unified accounts are not tenable. In turn, I will argue for a different and simplified right-branching structure that accounts for the syntax of measure words in question.

Following X. Li (2011), X. Li and Rothstein (2012) claim that a "measure" vs. "counting" difference corresponds to two different syntactic structures of measure words. They argue that the measure reading of measure words is expressed by a left-branching structure (i.e., (8a)), and the counting reading is expressed by a right-branching structure (i.e., (8b)).

a. Measure reading

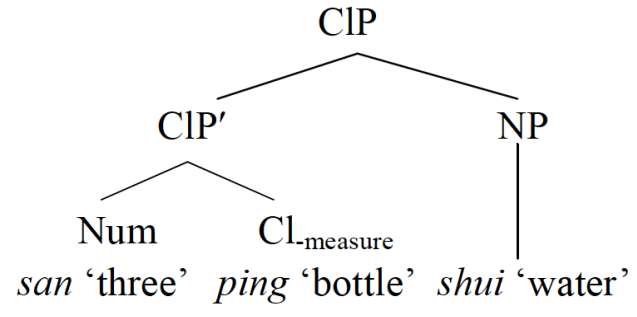

b. Counting reading

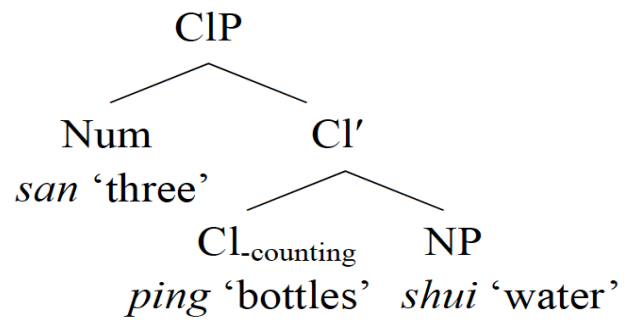


X. Li and Rothstein (2012: 709-710) propose that one classifier may carry either a measure reading or a counting reading. When it expresses a measure reading, the classifier and the numeral form "a complex classifier" that "combines" with NP through a left-branching structure (see also Tang 1990). Therefore, the numeral within the complex classifier is obligatory (e.g., (9a)). However, when a classifier expresses a counting reading, it heads a right-branching structure taking NP as its complement and the numeral as an optional modifier, e.g., (9b).

a. Measure reading

$\begin{array}{llllll}\text { Ta-de } & \text { jiuliang } & \text { shi } & *(y i) & \text { ping } & \text { hong-jiu. } \\ \text { his } & \text { drinking-ability } & \text { be } & \text { one } & \text { CL.bottle } & \text { red-wine }\end{array}$

'His drinking-ability is one bottle of red wine.'

b. Counting reading

$\begin{array}{lllllll}\text { Ta } & \text { zuo-shou } & \text { na } & \text { le } & \text { (yi) } & \text { ping } & \text { hong-jiu. } \\ \text { he } & \text { left-hand } & \text { take } & \text { PERF } & \text { one } & \text { CL } & \text { red-wine }\end{array}$

'He is crrying a bottle of red wine in his left hand.'

Nonetheless, there are some problems in this analysis. First, X. Li and Rothstein (2012) does not specify how the complex classifier in (8a) "combines" with the NP. According to X. Li (2011), the complex classifier modifies the NP, but the structure (8a) shows that the whole constituent is a Classifier Phrase. Second, the claim that the numeral expression in structure (8a) is part of a complex classifier is not empirically supported. Note that a numeral expression in the so-called "measure" reading can be as large as a phrase that normally does not undergo lexical head incorporation (e.g., chaoguo yi 'more than one' in (10)).

$\begin{array}{llllll}\text { (10) Ta-de jiuliang juedui } & \text { shi } & \text { chaoguo } & \text { yi } & \text { ping } & \text { hong-jiu. } \\ \text { his drinking-ability definitely } & \text { be } & \text { more.than } & \text { one } & \text { Cl.bottle } & \text { red-wine }\end{array}$ 'His drinking-ability is definitely more than one bottle of red wine.'

Third, Zhang (2013) points out that according to X. Li, the numeral-classifier sequence in (8a) modifies the noun, and thus, the modified NP cannot be deleted, unlike ( $8 b$ ) where the noun is the complement and can be deleted. However, Zhang (2013) shows that even under a measure reading, the so-called modified noun can still be deleted, as shown in (11) (see also (6)). Therefore, I render the analysis (8) not plausible.

(11) Baoyu yao mai san bang yingtao, Daiyu yao mai wu bang yingtar.

Baoyu want buy three pound cherry Daiyu want buy five pound

'Baoyu wants to buy three pounds of cherries, and Daiyu wants to buy five pounds.' 
Taking a different non-unified analysis, Zhang (2013) proposes that measure words expressing "individual, or individuating" readings head a Unit Phrase (i.e., UnitP in (12a)), whereas standard measurements and words expressing "collective, container, or partitive" readings require a left-branching structure, i.e., her Monotocity Phrase (MonP) in (12b).

a. Individual, individuating reading

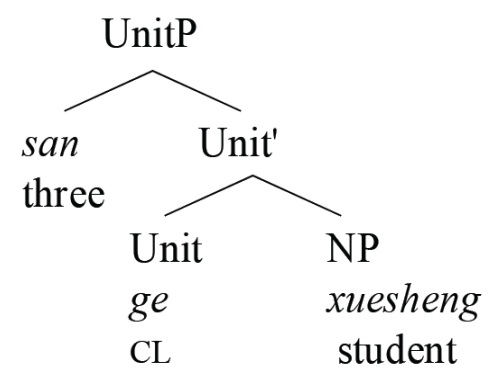

b. Collective, container, partitive readings and standard measurement

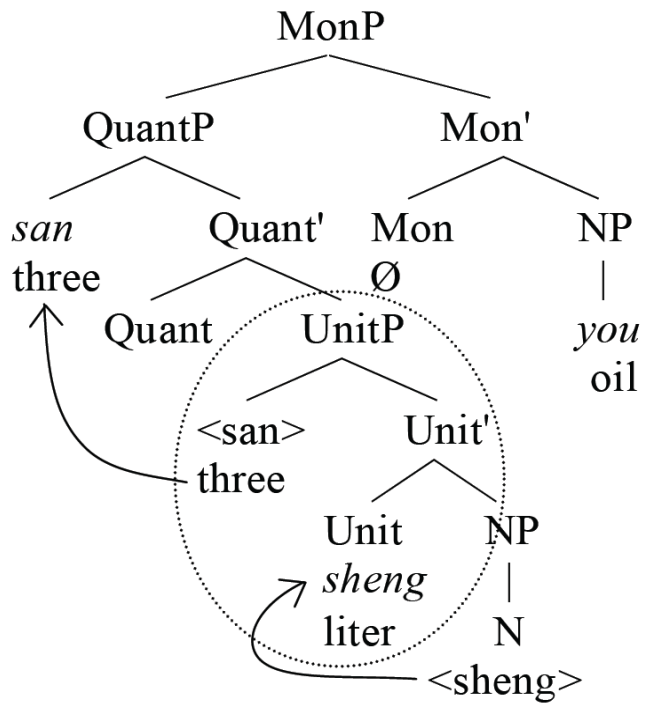

The motivation behind this non-unified account is essentially based on the fact that sometimes the modifiers of measure words can contradict modifiers of the noun.

(13) yuanyuan-de yi guan fang tang

round-DE one CL.jar square sugar

'a round jar of sugar cubes'

As shown in the example (13), the modifier of the measure word (yuanyuan-de 'round') contradicts the modifier of the noun (fang 'square'). Zhang argues that a left-branching structure is required in order to block such modifiers from c-commanding the NP, so that the scope of the left-peripheral modifier excludes the NP. 
However, unlike Zhang's proposals, I believe examples like (13) are exactly the supporting evidence for UnitP being an independent projection dominating NP. I argue that the occurrence of Unit head changes the semantic core of the whole nominal expression, and that the projection UnitP dominates the complement NP. In other words, examples like (13) show that the NP is indeed under the scope of the measure word guan 'jar'. That is, the sugar cubes in (13) have to be organized and referred as a unit of "a round jar", e.g., (14a) (vs. (14b)).

(14) a. a round jar of sugar cubes

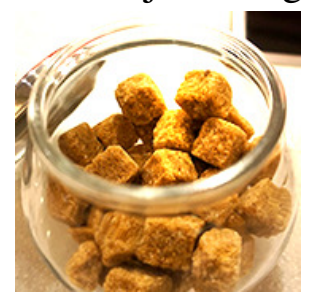

b. a square jar of sugar cubes

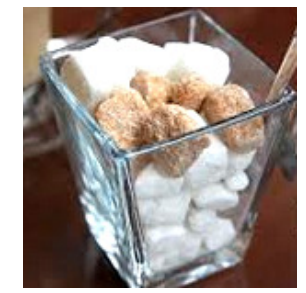

The examples in (15) demonstrate the same point. I argue that it is because UnitP dominates NP and expresses the semantic core of the whole nominal expression, the structure allows the modifiers of UnitP to be semantically contradict the modifiers of NP. ${ }^{4}$ This idea is not novel, just as TP is relevant to and is extended from $v \mathrm{P} / \mathrm{VP}$, and TP structurally c-commands $v \mathrm{P} / \mathrm{VP}$, but sentential adverbs only target TP; same as the relation between a transitive verb and its object $\mathrm{NP}$, where the semantic evaluation of the VP modifiers is semantically independent of the complement NP.

\begin{tabular}{|c|c|c|c|c|}
\hline Initi & $\begin{array}{l}\text { tebie } \\
\text { unusually }\end{array}$ & $\begin{array}{l}\text { hou-de } \\
\text { think-DE }\end{array}$ & $\begin{array}{l}\text { san } \\
\text { three }\end{array}$ & $\begin{array}{l}\text { pian } \\
\text { CL.piece }\end{array}$ \\
\hline
\end{tabular}
'three unusually thick pieces of thin bread'

4 In this paper, I do not consider examples like (i). It is known that examples with adjectives immediately precede classifier are rare, and usually only size adjectives, $d a$ 'big' and xiao 'small', can occur in such a position. I assume that such expressions are real complex classifiers that are formed morphologically before entering syntax.

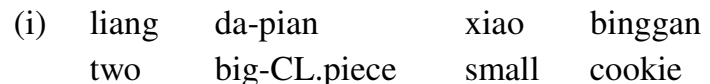
'two big-pieces small cookies'

Note that the adjective in the complex classifier does not perform like an adjective phrase. That is, it cannot be realized with the $d e$-marker (e.g., (iia)), and it cannot be modified by adverbs like hen 'very' (e.g., (iib)).

(ii) a.*liang da-de-pian xiao binggan

two big-de-CL.piece small cookie

$\begin{array}{lll}\text { b. *liang hen-da-pain } & \text { xiao } & \text { binggan } \\ \text { two very-big-CL.piece } & \text { small } & \text { cookie }\end{array}$ 


b. [UnitP hen $\begin{aligned} & \text { da-de san } \quad \text { ke } \\ & \text { very big-DE three }\end{aligned}$ CL
'three very-big-sized small apples'

As shown in the translation of examples in (15), the initial adjectives directly modify the Unit, rather than the NP. It is true that sometimes there is a correlation between the substance/individual and the unit/group of the substance/individual. When it is the case, we may find the modification of Unit extends to its following NP. I suppose that such semantic effects can also be explained through the current proposed structure (7) through c-command. In other words, I argue that the UnitP alone can also account for the same range of facts without complicating the syntax of measure words. Given the current proposal, one may predict that adjectives that only modify NP cannot modify UnitP. The prediction is supported by the contrast shown in (16).

$\begin{array}{lllll}\text { (16) a. [UnitP } & \text { san jian } & \text { [NP } & \begin{array}{l}\text { shiqian-de guwu] } \\ \text { three }\end{array} & \text { CL }\end{array} \quad \begin{aligned} & \text { prehistoric-DE antiquity }\end{aligned}$ 'three pieces of prehistoric antiquities'

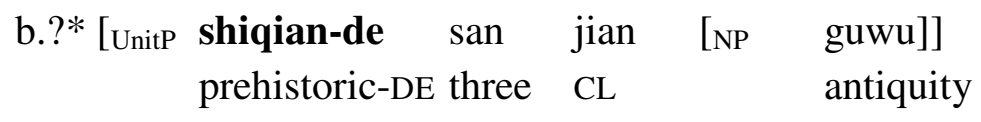

In sum, I argue that left-branching structures do not straightforwardly account for the phenomenon at issue, and facts discussed in this section in turn also cast doubts on non-unified accounts. In the next section, I compare the widely adopted right-branching analysis with my simplified right-branching proposal. I will show that the proposed UnitP is syntactically and phonologically motivated, and that the current proposal naturally accounts for other related phenomena.

\section{A Simplified Right-branching Analysis: the Unit Phrase}

In the literature, proposals that adopt a unified right-branching structure usually analyze Number Phrase (NumP) as an independent projection dominating Classifier Phrase (CLP), and the two projections in turn dominate NP (see Tang 1990, Cheng and Sybesma 1999, Li 1999, Borer 2005, and Huang, Li and Li 2009). 
(17) The widely adopted right-branching structure

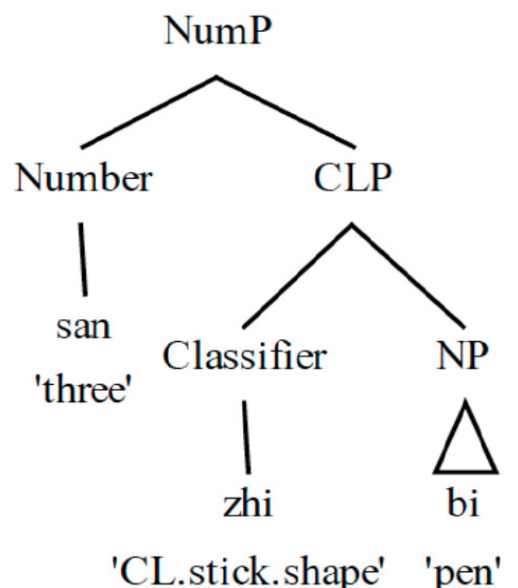

However, the structure (17) faces some empirical problems. In the following sub-sections, I show why (17) should not be adopted and how syntactic arguments as well as phonological arguments support the current proposal (7) (repeated below).

(7) Proposal: Unit Phrase

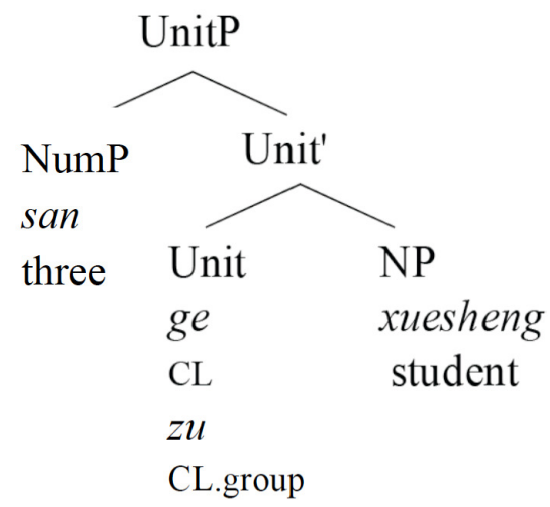

\subsection{Number Phrase Parasitic on Unit}

In this section, I show the structure (17) faces some empirical problems. First, a noun may occur alone or with a Unit, but a noun cannot be accompanied by a numeral alone.
(18)
a. Wo jian-guo [N gou $]$.
I see-EXP $\operatorname{dog}$
'I have seen dogs/a dog.'
b. Wo jian-guo [Unit zhi ] [N ${ }_{\mathrm{N}}$ gou $]$.
I see-EXP CL dog
'I have seen a dog.' 

c. *Wo jian-guo
[Number san ] [N
gou ].
I see-EXP
three
$\operatorname{dog}$
'I have seen three dogs.'

The contrast between (18a-b) and (18c) is not expected under the structure (17), if we assume that number, Unit, and noun are heads of individual projections, it is not clear why only the numeral behaves differently. Note that demonstratives can also co-occur with noun alone, like Unit.

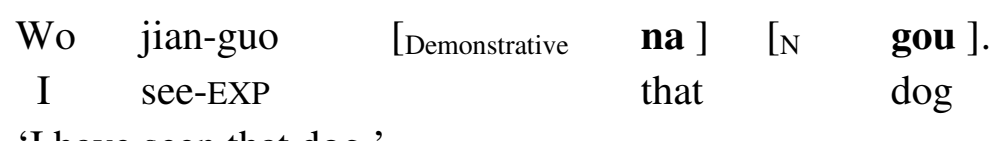

'I have seen that dog.'

Second, a numeral must always co-occur with a Unit within a nominal expression. The examples in (20) and (21) show that the grammaticality with or without Unit is consistant in both indefinite and definite expressions. Unit must occur in the nominal expression when there is a numeral.
(20) a. *Wo jian-guo san gou.
I see-EXP three dog
'I have seen three dogs.'

$\begin{array}{lllll}\text { b. Wo jian-guo } & \underline{\text { san }} & \text { zhi } & \text { gou. } \\ \text { I } & \text { see-EXP } & \text { three } & \text { CL } & \text { dog } \\ \text { 'I have seen three dogs.' } & & \end{array}$

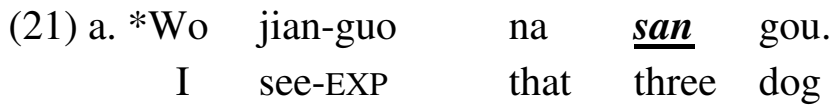
'I have seen those three dogs.'
b. Wo jian-guo na san zhi gou. I see-EXP that three CL dog 'I have seen those three dogs.'

In other words, numeral expressions are parasitic on the realization of Unit. If one postulates that Number Phrase dominates Unit (classifier) and noun, it is difficult to explain why the occurrence of the numeral always relies on the occurrence of classifier, a constraint not observed in other heads within nominals. Instead, the current analysis argues that Unit and $\mathrm{N}$ are head elements whereas number phrase is the specifier of UnitP. It structurally suggests that head elements can each co-occur with a noun, but number phrases is less independent, since it is the specifier of UnitP, unlike other heads. 


\subsection{The Distribution of Modifiers against NumberP > UnitP}

The distribution of relative clauses and adjectives also argues against (17) but supports the UnitP structure (7). Given the DP hypothesis proposed for Mandarin (see Li 1998, Hsieh 2005, Tang 1990, 2005, Huang et al. 2009), I show that a relative clause can occur before a DP (e.g., (22a)), between a demonstrative and a UnitP (e.g., (22b)), or between a classifier and an NP (e.g., (22c)). However, a relative clause never occur between a number phrase and a classifier, as shown in (23).

(22) a. [DP $[$ RC

meiren yao de] $\frac{n a}{\text { that }}$ shi ben shu ten CL book
nobody want DE
ten volumes of books, which nobody wants'

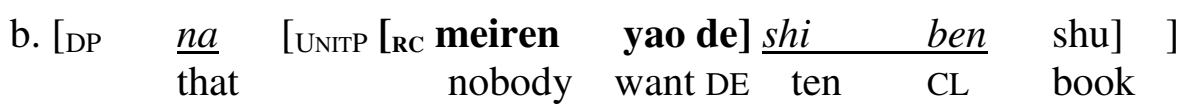
'those ten volumes of books that nobody wants'

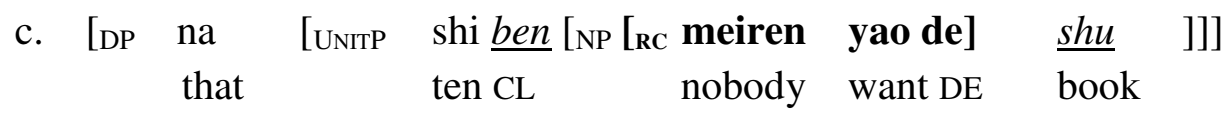
'those ten volumes of books that nobody wants'

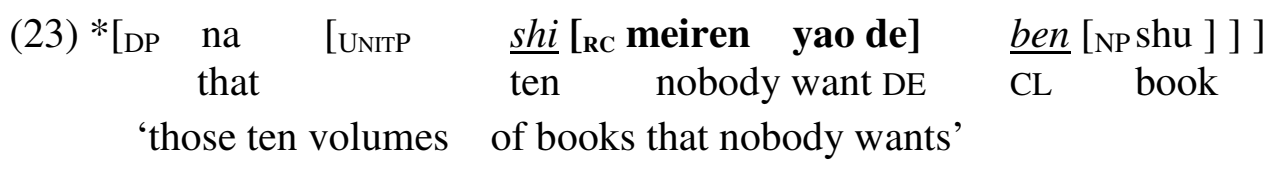

Assuming that a modifier may uniformly be introduced to the left-periphery of a phrase in Mandarin (see Huang 1982), and based on the structure (17), one may wonder why a relative clause is banned at the left-periphery of CLP (e.g., (23)). However, the contrast between (22) and (23) can be accounted for naturally under the proposed structure (7). I argue that each such phrase functions as the interpretive scope of the modifier (see (22)), and that since a numeral is the specifier of UnitP, modifiers cannot intervene between the numeral and Unit' (see (23)). The distribution of adjectives demonstrates the same point.

$\begin{array}{cclllll}\text { (24) a. }\left[\begin{array}{llll}\text { [he } & \text { gui } & \text { de }\end{array}\right] & \text { na } & \text { shi } & \text { ben } & \text { shu } \\ & \text { very pricy } & \text { DE } & \text { that } & \text { ten } & \text { CL } & \text { book }\end{array}$ 'those ten volumes of books, which are pricy'

\begin{tabular}{|c|c|c|c|c|}
\hline $\begin{array}{l}\text { b. [na [UnitP } \\
\text { that }\end{array}$ & $\begin{array}{l}\text { [hen gui } \\
\text { very pricy }\end{array}$ & $\begin{array}{l}\text { de] } \\
\mathrm{DE}\end{array}$ & $\begin{array}{l}\text { shi } \\
\text { ten }\end{array}$ & $\begin{array}{l}\text { ben } \\
\text { CL }\end{array}$ \\
\hline
\end{tabular}




c. [na $\left.\begin{array}{llllll}{[\text { shi }} & \text { ben } & {[\mathrm{NP}} & {[\text { hen gui }} & \text { de }] & \text { shu }]]\end{array}\right]$
that ten $\quad \mathrm{CL}$
'those ten volumes of books that are pricy'

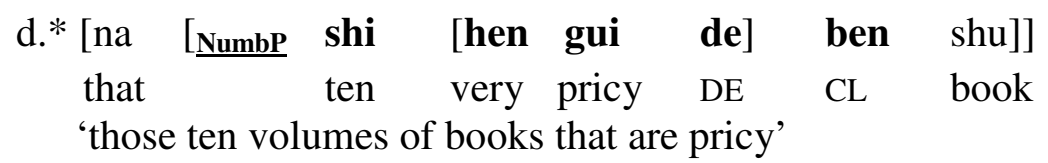

The examples in this section show that modifiers of nominal expressions show consistent distribution within a complex nominal, and that the proposed structure (7) naturally explains the distribution of adjectives and relative clauses, whereas the generally adopted structure (17) would wrongly generate expressions like (23) and (24d), or leave such facts unaccounted for.

\subsection{The Third Tone Sandhi against NumberP > UnitP}

The phenomenon of the third tone sandhi also supports the proposed structure (7). In Mandarin, the third tone [214] must undergo tone sandhi and become the second tone [35] when the syllable carrying [214] is followed by another syllable carrying [214]. An example of such sandhi rule application is shown in (25).

(25) Mandarin Third tone sandhi:

lao.shu 'mouse'

$\begin{array}{ll}\text { a. Underlying tone: } & \mathbf{2 1 4 . 2 1 4} \\ \text { b. Surface tone: } & \mathbf{3 5 . 2 1 4}\end{array}$

In addition to words and compounds, the third tone sandhi rule also applies within phrases and sentences. The generalization reported in the phonology literature is that when the structure is left-branching, only one sandhi pattern is observed, but when the structure is rightbranching, more than one pattern is available (see Duanmu 2005 and the references therein). While there is no consensus on the domain of application in phonology literature, interesting, if we pay closer attention to the syntactic structure of the data reported, we find that among the right-branching examples, the sandhi rule applies optionally between a head and its complement, however, if a phrase serves as a specifier/modifier of a head, the sandhi rule applies obligatorily. For instance, generally speaking, adverbs are analyzed as specifier/modifier of the head adverb or the head verb in an Adverb Phrase or a Verb Phrase, respectively. The examples in (26) show that adverbs and their head always form a prosodic unit, and the third tone sandhi rule always applies.

(26) a.

\begin{tabular}{llll} 
& [vP [AdvP [AdvP hen] & hao] & yang] 'very easy to raise' \\
& very & good & raise \\
Underlying tone: & 214 & 214 & 214 \\
Surface tone: & $\mathbf{3 5}$ & $\mathbf{3 5}$ & 214 \\
\hline
\end{tabular}


b.

\begin{tabular}{lll} 
& [vp [AdvP gan.jin ] \\
hurriedly & $\begin{array}{l}\text { mai] 'buy hurriedly' } \\
\text { buy }\end{array}$ \\
Underlying tone: & 214.214 & 214 \\
Surface tone: & $\mathbf{3 5 . 3 5}$ & 214 \\
\hline
\end{tabular}

Similarly, assuming that adjectives are specifier/modifier of the head noun, we can find examples like (27) show that the same tone sandhi phenomenon is observed between adjectives and nouns, i.e., the third tone sandhi rule is applied obligatorily.

(27) a.

\begin{tabular}{llll} 
& [NP [AdjP & hao] & jiu] 'good wine' \\
& & good & wine \\
Underlying tone: & 214 & 214 \\
Surface tone: & $\underline{35}$ & 214 \\
\hline
\end{tabular}

b.

$\begin{array}{llll} & \text { [NP [AdjP jue } & \text { mei } & \text { ] } \\ & \text { exceptionally beautiful } & \begin{array}{l}\text { jing.guan] 'splendid view' } \\ \text { landscape }\end{array} \\ \text { Underlying tone: } & 35 & 214 & 214.55 \\ \text { Surface tone: } & 35 & \mathbf{3 5} & 214.55\end{array}$

The third tone sandhi phenomenon provides another interesting argument supporting the proposed structure (7), but against (17). (28) shows that the third tone sandhi rule always applies between the numeral (wu bai 'five hundred') and the Unit (dang), although it can be optionally applied between the classifier (dang) and the noun (ying.pain 'movie') (cf. (28b) vs. (28c)).

$$
\begin{array}{lll}
\text { wu.bai } & \text { dang } & \text { ying.pian 'five hundred movies' } \\
\text { five.hundred } & \mathrm{CL} & \text { movie }
\end{array}
$$

a. Underlying tone: $\quad 214.214 \quad 214 \quad 214.51$

b. Surface tone:

$\underline{35.35} \quad 35 \quad 214.51$

Syntax structure: [UnITP

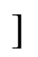

c. Surface tone:

$\underline{35.35}$

214

214.51

Syntax structure: [UnITP

[NP ] $]$

Following the generalization reported in the phonology literature, the two acceptable tonal patterns (28b) and (28c) show that the phenomenon at issue involves "right-branching structure", and thus, more than one tonal pattern is available. Next we need to consider why the third tone sandhi rule only optionally applies between Unit and NP. According to Cinque's (1993) Null Theory of Phrase Stress, when a complement is present, the complement is the stress bearer, rather than the head and the specifier, and specifiers/modifiers are always weak. Given the Mandarin data presented so far, I hypothesize that Cinque's proposal on phrasal stress assignment may be applied to the phenomenon of third tone sandhi within the phrasal domain in 
Mandarin. That is, the third tone sandhi rule obligatorily applies between the numeral and the classifier (e.g., (28b) and (28c)) since the numeral is the specifier of UnitP. The sandhi rule, however, has an option between the Unit and the NP: the sandhi rule can apply because two third tones are adjacent (e.g., (28b)), but it does not have to apply (e.g., (28c)) because NP is syntactically the complement of Unit.

Following the same reasoning, if one analyze a number phrase taking a classifier phrase as its complement (as in (17)), this analysis would wrongly predict that the sandhi rule can be optionally apply between the numeral and the Unit, contrary to the facts (e.g., (28) above vs. (29) below).
a. Underlying tone: five.hundred CL movie
b. *predicted tone:
35. 214
214
214.51
c. Syntax structure: $[$ NumP
$\left.\left[\begin{array}{ll}\mathrm{CLP} & {[\mathrm{NP}}\end{array}\right]\right]$

wu.bai

dang

The preceding examples show that the commonly adopted structure (17) faces empirical challenge syntactically and phonologially, but the current proposal (7) can correctly predict the distribution of modifiers, the third tone sandhi application, and the interpretation of modifiers within nominal expressions through a unified right-branching account. In Section 4, I show that this proposal further gain supports from phenomena of nominal coordination and nominal internal ellipsis.

\section{The Structural Prediction of UnitP}

\subsection{Nominal Coordination}

The proposed structure (7) echoes an observation on nominal coordination in Mandarin reported by Aoun and Li (2003). Aoun and Li point out that coordinators in Mandarin exhibit categorical restriction. Coordinator that are relevant to nominal expressions are summarized in (30).
a. jian 'and': coordinates two NPs
b. he 'and': coordinates two DP

The example in (31) shows that when two phrases lower than the UnitP (their classifier) are coordinated, jian 'and' is used, but not he 'and'. 


$$
\begin{aligned}
& \text { Wo xiang zhao yi ge [NP [RC fuze yingwen de] [NP mishu] } \\
& \text { I want find one CL charge English DE secretary }
\end{aligned}
$$

$\begin{array}{lrllll}\text { jian/*he } & {\left[\begin{array}{lll}\text { NP }[\text { RC jiao } & \text { xiaohai } & \text { de }\end{array}\right.} & {\left[\begin{array}{lll}\text { NP } & \text { jiajiao }]\end{array}\right] .} \\ \text { and } & \text { teach } & \text { kid } & \text { DE } & & \text { tutor }\end{array}$

'I want to find a person who can be a secretary that takes care of English (matters) and can be kids' tutor.'

Nonetheless, when two conjuncts both have demonstratives, only he 'and' is allowed, e.g., (32).

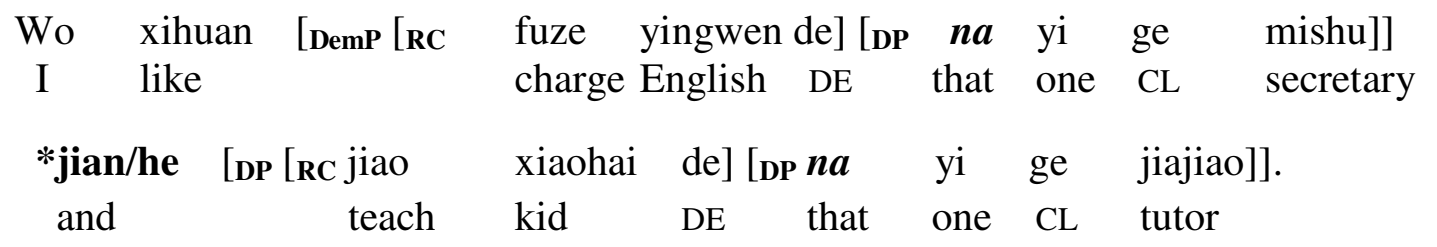

'I like the secretary who takes care of English (matters) and the tutor that teaches kids.'

Based on the proposed structure (7), one may predict that UnitPs can be coordinated. The example in (33) shows that the relative clauses signal the maximal UnitP are coordinated, and that UnitPs are coordinated by $h e$ 'and'.

(33) Wo xihuan $\boldsymbol{n a}$ [UnitP [RC fuze yingwen de] [unitP san wei mishu ]] I like that charge English DE three CL secretary *jian/he [UnitP [RC jiao xiaohai de] [UnitP liang wei jiajiao]]. and teach kid DE two CL tutor

'I like those three secretaries who take care of English (matters) and those two tutors that teach kids.'

Note that no matter which coordinator is used, trying to coordinate two numeral phrases is not allowed in Mandarin.

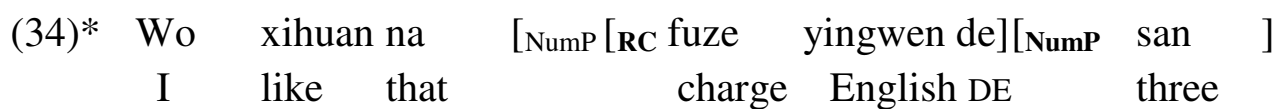

jian/he [umP [RC jiao xiaohaide] [NumP liang wei mishu ]]. and teach kid DE two CL secretary

'I like those three secretaries who take care of English (matters) and those two tutors that teach kids.' 


\subsection{Nominal Internal Ellipsis}

Following Lobeck that ellipsis is licensed by a functional head and following Merchant (2001) that structural identity is respected in ellipsis, I show that sentences with ellipsis support the proposed structure, i.e., the ellipsis site can be NP or UnitP.

Example (35) shows that the elided part can be recovered from its antecedent NP, shangyi 'shirt'. Note that the presence of Unit jian (the classifier of clothes) to the left of the ellipsis site suggests that what is elided in this sentence indeed is an NP.

(35) NP

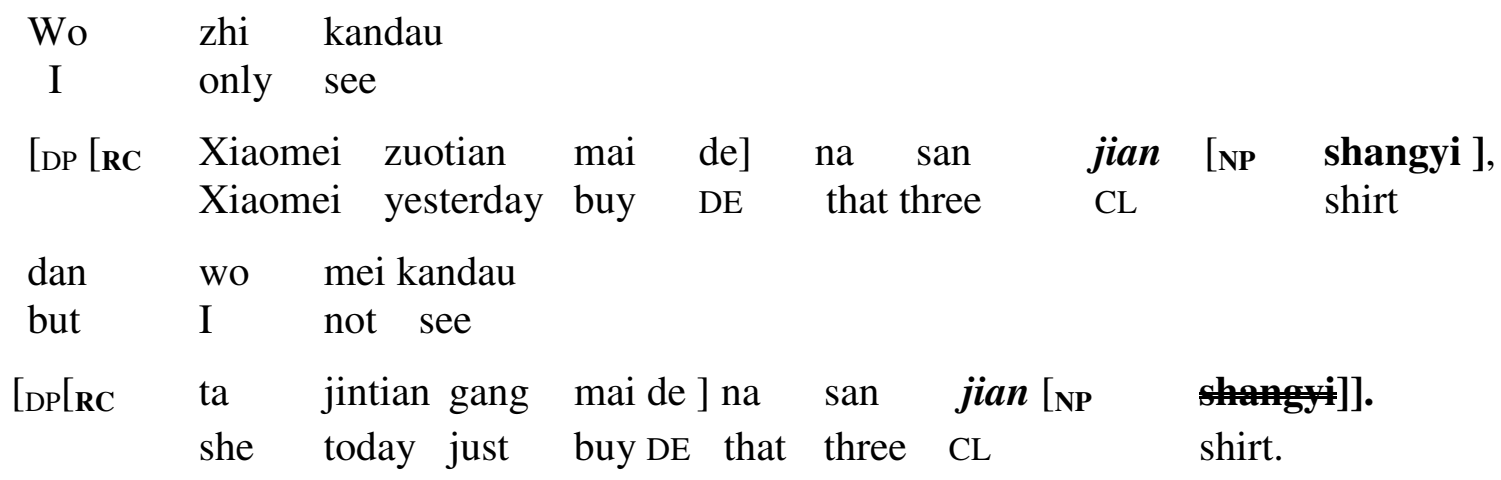

'I only see those three shirts that Xiaomei bought yesterday, but I don't see those three [shirts] that she just bought today.'

A similar effect is found with respect to UnitP. (36) shows that ellipsis targets the UnitP, san jian shangyi 'three shirts,' which is embedded inside of a DP.

\section{UnitP}

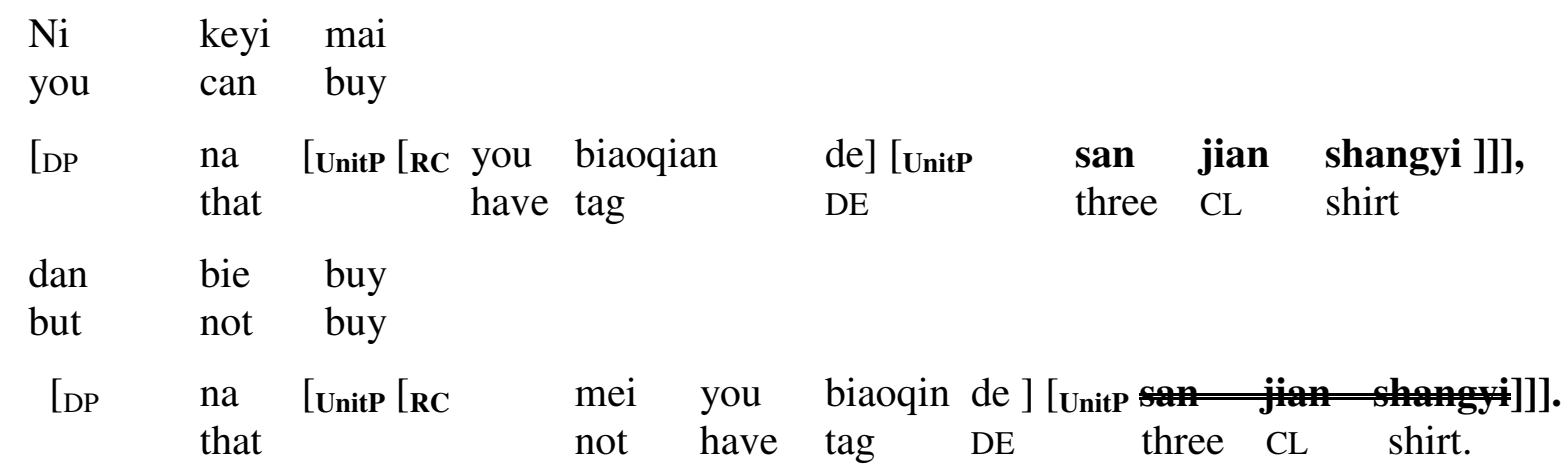

'You could buy those three shirts with tags, but should not buy those [three shirts] without tags.' 
However, unlike the current analysis, an analysis adopting (17) would not be able to directly explain the following ungrammatical example in which the classifier phrase that is analyzed as the complement of number is elided.

\section{NumberP}

\begin{tabular}{|c|c|c|c|c|c|c|c|}
\hline $\begin{array}{cl}* \text { Wo } & \text { zhi } \\
\text { I } & \text { only }\end{array}$ & $\begin{array}{l}\text { kandau [DP } \\
\text { see }\end{array}$ & $\begin{array}{l}\text { zhe } \\
\text { this }\end{array}$ & $\begin{array}{l}\text { san } \\
\text { three }\end{array}$ & {$[\mathrm{ClP}$} & $\begin{array}{l}\text { jian } \\
\mathrm{CL}\end{array}$ & {$[\mathrm{NP}$} & $\begin{array}{l}\text { shangyi ]]]], } \\
\text { shirt }\end{array}$ \\
\hline dan & mei & kandau [DP & & {$[$ NumP } & & felp & jian $[\mathrm{NP}=$ shangyi]]]]. \\
\hline
\end{tabular}

'I only saw these three shirts, but I don't see those three [shirts].'

The preceding discussion shows that UnitP is syntactically dominating NP but NumP is better analyzed as the specifier of UnitP. In the following sections, I will show how the proposed structure helps us explain the facts related to the interpretations of nominal expressions.

\section{$5 \quad$ Syntax-Semantics Correlations}

The proposal suggests that a nominal expression in Mandarin may be realized as a phrase of distinct size (e.g., DP, UnitP, NP). I have shown that a nominal expression in Mandarin may appear as Noun alone or as Noun accompanied by one or both of Demonstrative and Unit. However, Number appears only contingently on the introduction of Unit, as expected under the proposed analysis in (7). I argue that measure words should be analyzed as UnitP that changes the semantic core of the whole nominal expression. That is, the realization of UnitP syntactically expresses quantity and or measurement of a defined unit of nouns.

To begin, given the proposed structure, one may infer that when the UnitP is projected as the highest projection of a nominal, such an expression only denotes quantity of a unit, and that such an expression would not be referential. The conjecture is borne out. Example (38) shows that the quantity-denoting adverb yigong 'altogether' is not compatible with a referential DemP, but only with UnitP. ${ }^{5}$

\begin{tabular}{|c|c|c|c|c|c|c|c|}
\hline a. & $\begin{array}{l}\text { Ta } \\
\text { he }\end{array}$ & $\begin{array}{l}\text { yigong } \\
\text { altogether }\end{array}$ & $\begin{array}{l}\text { mai-le } \\
\text { buy-PERF }\end{array}$ & [UnitP & $\begin{array}{l}\text { wu } \\
\text { five }\end{array}$ & $\begin{array}{l}\text { ben } \\
\text { CL }\end{array}$ & $\begin{array}{l}\text { shu ]. } \\
\text { book }\end{array}$ \\
\hline & & 'His purchasi & $\mathrm{g}$ of books & otaled 5 & olun & & \\
\hline b. & $\begin{array}{c}\text { \#Ta } \\
\text { he }\end{array}$ & $\begin{array}{l}\text { yigong } \\
\text { altogether }\end{array}$ & $\begin{array}{l}\text { mai-le } \\
\text { buy-PERF }\end{array}$ & $\begin{array}{l}\text { [DP zhe } \\
\text { this }\end{array}$ & $\begin{array}{l}\text { wu } \\
\text { five }\end{array}$ & $\begin{array}{l}\text { ben } \\
\text { CL }\end{array}$ & $\begin{array}{l}\text { shu } \\
\text { book }\end{array}$ \\
\hline
\end{tabular}

'He bought altogether these five books.'

\footnotetext{
${ }^{5}$ The sentence in (38b) may become acceptable when the speaker is pointing at five books that are physically present. The pragmatic effect involved is outside of the scope of the current study, so I leave the explanation for future study.
} 
Moreover, it is known that a nominal expression containing only number-Unit-Noun is not referential, unlike a nominal expression containing a demonstrative. Under the proposed structure, it suggests that UnitP cannot co-refer with or bind a pronoun but a DP can. The contrast in example (39) shows that a UnitP is not referential, whereas a DP is.
a. *[UnitP
San ge
$\left.\operatorname{ren}_{i}\right]$
tai-bu-qi liang jia ni gei
gei tamen $_{\mathrm{i}}$-de gangqin. three CL
man lift-not-up two
CL you give
them -DE piano

'Three people cannot lift two (of the) pianos that you gave to them.'

(from Huang et al. 2009:290, modified with the proposed structure)

b. [DP Na san ge ren ${ }_{i}$ ] tai-bu-qi liang jia ni gei $\operatorname{tamen}_{\mathrm{i}}$-de gangqin. that three CL man lift-not-up two CL you give them -DE piano

'Those three people cannot lift two (of the) pianos that you gave to them.'

In sum, I argue that measure words at issue should be analyzed as the head of UnitP, and that the realization of UnitP changes the semantic core of the whole nominal, and its complement NP is perceived and interpreted under the scope of UnitP. Based on the proposed structure, we also have a way to structurally distinguish nominal expressions that only denote quantity or measurement from DP and NP.

\section{Concluding Remarks}

In this paper, I argued that UnitP should be identified as a distinct projection dominating NP in Mandarin. This paper showed that the proposed structure accounts for the distribution of nominal modifiers, the restriction of the occurrence of numeral, Unit, and Noun within a nominal, and the third tone sandhi application. I showed that the realization of UnitP changes the semantic core of the whole nominal, and that NP is under the scope of UnitP. I had also shown that quantity denoting adverbs are only compatible with UnitP, and that UnitP is not referential, unlike DP. The proposed structure also directly and correctly predicts the realization of nominal coordination and nominal internal ellipsis, and provides a simpler way to explain the phenomenon at issue through a unified account.

\section{$7 \quad$ References}

Aoun, Joseph, and Yen-hui Audrey Li. 2003. Essays on the representational and derivational nature of grammar. Cambridge: MIT Press.

Borer, Hagit. 2005. In name only. New York: Oxford University Press.

Cheng, Lisa Lai-Shen and Rint Sybesma. 1998. Yi-wan tang, yi-ge tang: Classifiers and massifiers. Tsing-Hua Journal of Chinese Studies 28(3):385-412.

Cheng, Lisa Lai-Shen and Rint Sybesma. 1999. Bare and not so bare nouns and the structure of NP. Linguistic Inquiry 30.4: 509-542. 
Cinque, Guglielmo. 1993. A null theory of phrase and compound stress. Linguistic Inquiry 24: 239-298.

Duanmu, San. 2005. The Tone-Syntax Interface in Chinese: Some Receont Controversies. Proceedings of the Symposium "Cross-Linguistic Studies of Tonal Phenomena", S. Kajji (ed.), pp221-254. Institute for the Study of Languages and Cultures of Asia and Africa, Tokyo University of Foreign Studies. http://wwwpersonal.umich.edu/ duanmu/ToneSyntax05.pdf

Her, One-Soon. 2012. Structure of classifiers and measure words: a lexical functional account. Language and Linguistics 13:1211-1251.

Hsieh, Miao-Ling. 2008. The internal structure of noun phrases in Chinese. Taipei: Crane Publishing Co.

Huang, C.-T. James. 1982[1998]. Logical Relations in Chinese and the Theory of Grammar. New York \& London: Garland Publishing, Inc.

Huang, C.-T. James., Audrey Li and Yafei Li. 2009. The Syntax of Chinese. Cambridge University Press.

Merchant, Jason. 2001. The Syntax of Silence: Sluicing, Islands, and the Theory of Ellipsis. Oxford, Oxford University Press.

Li, Audrey Yen-hui. 1998. Argument Determiner Phrases and Number Phrases. Linguistic Inquiry 29: 693-702.

Li, Xu-Ping. 2011. On the semantics of classifiers in Chinese. Bar-Ilan University Ph.D. dissertation.

Li, Xu-Ping, and Susan Rothstein. 2012. Measure readings of Mandarin classifier phrases and the particle de. Language and Linguistics 13(4): 693-741.

Shi, Ding-xu. 2013. Mass Nouns, Countable Nouns, Massifiers and Classifiers. Paper presented at Workshop on the Grammar of Measurement in Chinese, held in conjunction with IACL-21.

Tang, Chih-chen Jane. 1990. Chinese Phrase Structure and the Extended X'-Theory. Ph.D. dissertation, Cornell University.

Zhang, Niina Ning. 2011. The constituency of classifier constructions in Mandarin Chinese. Taiwan Journal of Linguistics 9.1:1-50.

Zhang, Niina Ning. 2013. Classifier Structures in Mandarin Chinese. Berlin: Mouton de Gruyter. 